\section{$\underset{\substack{\text { hommes } \\ \text { \& migrations }}}{ }$}

\section{Hommes \& migrations}

Revue française de référence sur les dynamiques

migratoires

1323 | 2018

Persona grata

\title{
Babels, Entre accueil et rejet : ce que les villes font aux migrants
}

Lyon, Le Passager clandestin, coll. « Bibliothèque des frontières », 2018, 120 pages, $10 €$

\section{Marie Poinsot}

\section{(2) OpenEdition}

1 Journals

\section{Édition électronique}

URL : https://journals.openedition.org/hommesmigrations/7947

DOI : 10.4000/hommesmigrations.7947

ISSN : 2262-3353

Éditeur

Musée national de l'histoire de l'immigration

\section{Édition imprimée}

Date de publication : 1 octobre 2018

Pagination : 216-217

ISBN : 978-2-919040-42-1

ISSN : 1142-852X

\section{Référence électronique}

Marie Poinsot, «Babels, Entre accueil et rejet: ce que les villes font aux migrants », Hommes \& migrations [En ligne], 1323 | 2018, mis en ligne le 01 octobre 2018, consulté le 08 janvier 2022. URL : http:// journals.openedition.org/hommesmigrations/7947; DOI : https://doi.org/10.4000/ hommesmigrations.7947 


\section{Babels, Entre accueil et rejet : ce que les villes font aux migrants}

Lyon, Le Passager clandestin, coll. «Bibliothèque des

frontières », 2018, 120 pages, $10 €$.

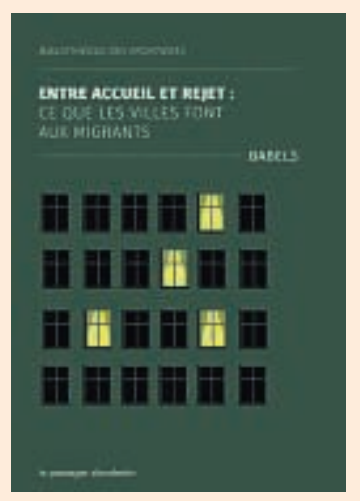

Dans la collection «Bibliothèque des frontières», ce troisième volume coordonné par Véronique Bontemps, Chowra Makaremi et Sarah Mazouz, est consacré à l'accueil des migrants dans les villes européennes. Cet ouvrage propose utilement un état de l'art sur les travaux parus sur le thème "villes et migrations » et définit de nouvelles pistes de recherche présentées par des équipes pluridisciplinaires en Europe. Il montre que l'attitude générale des villes varie en fonction de la géographie des circulations migratoires des migrants/réfugiés sur le territoire européen (l'effet-frontières) et il propose une typologie de «villesrefuge» et de «villes-rejet» en Europe à partir de l'analyse de villes emblématiques (Paris, Berlin, Istanbul, et des villes du Danemark, Belgique, Espagne et Italie). Si les contextes urbains constituent un facteur explicatif dans les «performances» des villes européennes à accueillir les migrants (développement économique, quartiers dits «techniques», structuration sociale, densité du logement social, gentrification, cosmopolitisme, etc.), «les pratiques d'accueil ou de rejet des migrants dans les villes européennes sont d'abord liées aux effets de politiques publiques...». Les inscriptions territoriales des migrants dépendent de ces contextes, notamment en termes de campements urbains et ou de résorption des nouveaux bidonvilles mais ils influent aussi en retour sur les expériences migratoires en favorisant des (re)constructions personnelles contre la dureté ou le traumatisme liés aux déplacements et aux contrôles policiers. L'ouvrage montre la nécessité d'appréhender la relation ville-migration en identifiant les jeux complexes des acteurs territoriaux (États, les élus municipaux, les associations et les collectifs divers et les habitants) et leurs interactions en matière d'actions publiques qui suivent selon les villes des logiques communes, concurrentes, en tensions ou conflits. La situation française se caractérise par une politique municipale de gestion d'urgence en réponse à la politique migratoire sécuritaire et restrictive menée par l'État qui crée une pression constante autour de l'arrivée des migrants dans les quartiers parisiens. «De 2015 à 2017, il y eut 35 évacuations et autant de campements reformés, qui ont dessiné une nouvelle carte du Nord-Est parisien, à mesure que ces espaces évacués se couvraient de grillage et que les noms des rues et de lieux (Pajol, Eole, Jaurès, Flandres...) acquéraient une nouvelle connotation affective, synonyme, pour certains habitants, d'expériences politiques et collectives et de rencontres humaines; pour d'autres, de désordre et de peur du déclassement.» Une partie de l'ouvrage est consacré aux logiques de délocalisation des flux de nouveaux arrivants vers les villes moyennes, voire vers les espaces ruraux qui s'avèrent utiles pour éviter les «encampements» et la forte visibilité des migrants dans les villes. Ce que les 
migrants font aux villes? Cette partie conclusive de l'ouvrage, montre comment l'hospitalité privée, celles des migrants et de leurs communautés, intervient activement sur les conditions d'installation des migrants. Les quartiers qui ont une histoire migratoire ancienne peuvent mobiliser, à travers l'engagement des populations locales, les mémoires des générations migratoires passées pour changer les regards sur les migrants d'aujourd'hui en fabriquant des images moins victimaires, positives et entreprenantes et accompagner les actions d'accueil des migrants d'aujourd'hui. Plus généralement, la mobilisation des citoyens, parfois en dehors des canaux habituels de l'engagement politique et au nom de l'hospitalité et de la solidarité, constitue un rempart face à la montée des racismes et des attitudes de rejet qui se manifestent aussi dans les villes face à la visibilité urbaine des migrations. "Ainsi, dans le contexte d'anxiété identitaire qui se formule par la fermeture des frontières, le confinement et les expulsions, ce qui se joue au niveau des villes peut apparaître comme un principe d'inquiétude démocratique salutaire. » Cet ouvrage est un recueil synthétique et accessible dans son style d'expériences menées par les villes à des échelles différentes et par une pluralité d'acteurs. Il est une ressource utile pour les débats, les mobilisations locales et l'orientation de l'action publique dans ce domaine.

Marie Poinsot 